\title{
On Correlations between Range in Verb DESCRIPTIVITY AND SyNTACTIC APPlicability
}

\begin{abstract}
The paper attempts to identify factors underlying apparent correlations between the level of descriptivity in verbs of self-agentive locomotion and the range of syntactic constructions in which these verbs may occur. While it has become clear that event structure theories provide a partial account of the connections between verbal semantics and syntactic behaviour, Boas's account $(2006,2008)$, deriving from the theory elaborated by Snell-Hornby (1983), would seem to be on the right track in offering a more fine-grained analysis of verbal lexical semantic structure. What remains to be answered is which elements of a verb's meaning are syntactically relevant and what underlies their sensitivity to syntax. The paper argues that an account of a verb's syntactic applicability must appeal to the interaction between the verb's lexical semantic structure and the causal structuration of a situation as encoded in a given construction.
\end{abstract}

Keywords

Verbs of self-agentive locomotion; verbal lexical semantic structure; syntactic alternations; constructional meaning; syntactically relevant elements of verbal meaning; causal structuration

\section{Introduction}

The exact nature of the relation between a verb's semantic structure and the verb's syntactic behaviour is, to a large extent, an unresolved question. Although linguists now generally agree that in order for a verb to participate in a construction, a verb's meaning must in some way be compatible with the meaning inherent in the construction itself, the principles governing the interaction between verbal semantic structure and the semantics of a construction are still not fully clear (for 
a very systematic and in-depth comparison of lexicalist and constructional approaches see Chapter 6 in Croft 2012). The nature of the relation between verbal meaning and syntactical patterns into which verbs may enter has been the subject of intensive debate, especially since the publication of Levin's (1993) seminal work on verbal meaning and argument structure alternations, which brought robust evidence in favour of the essentially lexical-semantic motivation of verbs' ability to participate in diathesis alternations. Nevertheless, it has become apparent that heavy reliance on syntactic data is not without problems. Apart from extensive cross-listing, Levin's account sometimes results in positing verbal classes that are semantically largely heterogeneous (cf. Baker and Ruppenhofer 2002). Boas (2011) observes that the explanatory nature of alternations should not be overestimated because "syntactic alternations are an epiphenomenon caused by a significant type frequency of semantically related verbs" (2011: 230). Alternations as a way of probing for verbal meaning are also argued against by Goldberg (2002). She claims that verb-argument structure is realized in syntagmatic surface structure and that "it is profitable to look beyond alternations and to consider each surface pattern on its own" (2002: 327).

This paper sets out to show that alternations do provide an important insight into verbal semantics with the proviso that an account of verbal syntactic behaviour involves a fine-grained analysis of verbs' lexical semantic structure. The analysis presented in the paper derives from an account offered by Boas (2006 and 2008), which claims a correlation between a degree of a verb's descriptivity (roughly, a specificity and complexity of a verb's meaning) and a degree of a given verb's syntactic applicability. Apart from offering a restructured classification of the degrees of descriptivity of the verbs under analysis (a set of verbs of selfagentive locomotion), the paper attempts to identify verbal meaning components that are syntactically relevant and points to reasons underlying their sensitivity to syntax.

\section{Approaches Involving a Bifurcation of Verbal Semantic Structure}

Jackendoff's (e.g., 1983, 1990) account involves a bifurcation of verbal semantic structure into syntactically relevant components and syntactically irrelevant components. In his conception, syntactically relevant parts of verbal meaning belong to conceptual structure, whereas syntactically irrelevant parts, providing mere perceptual (3D) information, belong to spatial structure. For example, the verbs run, jog, strut or lope only differ in the associated 3D model, not in their conceptual structure, and thus are syntactically parallel (Jackendoff 1990: 34). However, the claim that meaning components providing perceptual information about a manner of motion are syntactically irrelevant cannot be maintained. It is far from being the case that manner of motion verbs behave in a uniform way. For example, in comparison with run, the verb strut exhibits a restricted behaviour: He ran her to the door - *He strutted her to the door, He ran himself to 
exhaustion - *He strutted himself to exhaustion, He ran himself to the door $-* H e$ strutted himself to the door. As argued for by Taylor (1996), skeletal semantic representations in the vein proposed by Jackendoff cannot adequately capture the basic meanings of verbs. Deriving from an analysis of the semantic and syntactic differences between the verbs run and jog, Taylor further argues that the division of a verb's meaning into a syntactically relevant component and a syntactically irrelevant component should be rejected. He claims, instead, that an adequate description of the meanings of the two verbs and of their syntactic behaviour (which is, as he demonstrates, in many ways different) must appeal to encyclopaedic knowledge, which is neither exclusively conceptual nor exclusively perceptual.

Event structure theories classify verbs into classes according to the type of their event structure (a representation of syntactically relevant lexical semantic elements), which is viewed as the crucial factor determining verbs' syntactic behaviour (e.g., Dowty 1979, Rappaport Hovav and Levin 1998, Van Valin and LaPolla 1997). Rappaport Hovav and Levin (1998) propose a division of a verb's meaning into an event structure, which is shared by all verbs belonging to a given event type, and a root, which represents an idiosyncratic component of a verb's meaning. The event structure template for self-agentive verbs of manner of locomotion has the following form:

$$
\left[\mathrm{x} \mathrm{ACT}_{<\mathrm{MANNER}}\right] \text { (e.g., run, jog, walk...) }
$$

The notation indicates that self-agentive manner of locomotion verbs are all activities involving an agent as a single participant. The predicate ACT is a primitive predicate; its subscript (a modifier constant) specifies a manner of motion. Rappaport Hovav and Levin contend that verbs of manner of motion share the same event structure and therefore behave in a uniform way. That is, idiosyncratic components of meaning are not syntactically relevant and merely differentiate among verbs belonging to the same event type. Rappaport Hovav and Levin illustrate the point in the example of the verb run, which they claim displays a behaviour common to all manner of motion verbs (1998: 98):
a. Pat ran.
b. Pat ran to the beach.
c. Pat ran herself ragged.
d. Pat ran her shoes to shreds.
e. Pat ran clear of the falling rocks.
f. The coach ran the athletes around the track.

However, as pointed out by Boas (2006 and 2008) and Kudrnáčová (2008), the claim that verbs of manner of motion display a uniform behaviour and that idiosyncratic components of their meaning have a mere differentiative function suffers from overgeneralization and is not attested by language data. Consider some illustrative examples taken from Boas (2008: 24): 
(2) a. The coach ran the athletes around the track.

b. ?The coach jogged the athletes around the track.

c. *The coach staggered the athletes around the track.

d. *The coach ambled the athletes around the track.

As can be seen, the argument structures of the verbs jog, stagger and amble cannot be augmented in a way exhibited by run. Although these verbs belong to the same category (they are monadic verbs expressing a manner of self-agentive locomotion), they display variable behaviour.

\section{Boas's Multi-faceted Approach}

Boas $(2006,2008)$ brings strong arguments in favour of syntactic relevance of a root-based meaning. He advocates a novel approach combining frame semantics, lexical decomposition and verb descriptivity. ${ }^{1} \mathrm{He}$ offers a detailed analysis of the semantic structure of 20 verbs evoking the Self_motion frame. The theory of semantic frames (Fillmore 1982, 1985) rests on the idea that a concept denoted by a word carries supplementary information evoking a distinct semantic frame, which describes the overall situation implied by a word's meaning. That is, the semantic representation of a word also includes situational and background knowledge. The FrameNet approach thus derives from primarily semantic criteria and groups together verbs that evoke the same situation (a specific scenario involving certain types of participants). The FrameNet specifies the Self_motion frame as prototypically involving individuals moving under their own power by means of their bodies, i.e. the Self_motion frame prototypically includes verbs denoting some manner of self-agentive locomotion. The frame includes the following core frame semantic elements: Area (The mouse scurried about), Direction (You should walk south about a block), Goal (The children skipped into the park), Path (The scouts hiked along the river), Source (The cat ran out of the house) and the Self_mover (Fred crawled the narrow passage). ${ }^{2}$ The Self_mover is a living being which moves under its own power and is normally expressed as an external argument.

Apart from frame semantics, Boas also draws on Snell-Hornby's (1983) theory of verb descriptivity. Snell-Hornby identifies two essential meaning components in verbal lexical semantic structure: the act nucleus and the modificant. To give an example, the act-nucleus (i.e. a verb core) of strut is walk and the modificant is "a semantic complex further analyzable into visible physical characteristics (stiff, erect) and value-judgements passed on the character of the agent and his manner of walking (self-satisfied, proud, pompous, with affected dignity), resulting in the speaker's negative evaluation of both agent and act" (Snell-Hornby 1983: 25). By virtue of its modificant the verb strut not only states a verbal action but also describes it; it is thus termed a 'descriptive verb'.

Boas's analysis bears out Snell-Hornby's prediction claiming a connection between the complexity of a verb's modificant and a verb's syntactic elasticity: the 
higher the degree of descriptivity, the lower the number of syntactic constructions available for the verb (Snell-Hornby 1983: 34). In concrete terms, the more complex the modificant is and the greater prominence it has with respect to the act-nucleus, the higher the degree of a verb's descriptivity. To illustrate the point in detail, Boas offers a comparative analysis of the degree of descriptivity of the verbs walk, parade, totter and stagger (2006: 141-143, 2008: 31-32). He suggests the following ranking of the verbs in the order reflecting rising degrees of descriptivity:

$$
\text { walk }<\text { parade }<\text { totter }<\text { stagger }
$$

Walk is the least descriptive. The act-nucleus is the most prominent, whereas the modificant is of minor weight. The modificant only implies that the movement "takes place on foot, presumably at a normal speed and with an upright posture" (Boas 2008: 35). The act-nucleus of parade loses in prominence while the modificant gains in weight. The modificant is relatively complex in that the description of the self-mover "presents a close-up view of the moving activity, focusing on the individual steps taken in a controlled regular manner, often in an energetic way and as a part of a procession to show off" (Boas 2008: 31). In totter, the modificant is even more prominent: the steps of the self-mover deviate from the norm of regular intervals; the self-mover may also have difficulties maintaining an upright posture, which may be caused by weakness or intoxication. Finally, stagger displays the highest degree of descriptivity. Its act-nucleus is the least prominent and its modificant is the most complex. The self-mover has even less control over its movement and has severe difficulties to maintain an upright posture, typically due to problems with balance.

Boas employs the following grammatical patterns to prove the correlation between verbs' descriptivity and their syntactic applicability (the illustrative examples are taken from Boas 2006: 143):

Inclusion of a location PP: Gerry walked (/paraded/staggered/ tottered) down the street.

Locative preposition drop construction:Julia walked (/paraded/*staggered $/$ *tottered) the town.

Induced action alternation: Claire walked (/paraded/*staggered /*tottered) the dog down the street.

Caused-motion construction: Cathy walked (/*paraded $/ *^{*}$ staggered $/ *$ tottered) Pat off the street.

Resultative construction: Cathy walked (/?paraded/*staggered /*tottered) herself to exhaustion.

Zero-related nominal: a walk, a parade, a stagger, a totter

Adjectival passive participle: the walked (/??paraded /*staggered/*tottered) $\operatorname{dog}$ 
Deriving from the analysis of the verbs' lexical semantic structure and their usability in a given set of grammatical patterns, Boas comes to the conclusion that the degree of the verbs' descriptivity is indeed correlated with the degree of their syntactic applicability, and proposes the following classification:

$1^{\text {st }}$ group: walk

$2^{\text {nd }}$ group: jog, jump and waltz

$3^{\text {rd }}$ group: bustle, hike, parade, swim

$4^{\text {th }}$ group: amble, crawl, creep, frolic, limp, meander, scurry, stagger, totter, trot, wade, wander

The groups are ranked in the order which reflects the gradual decrease in the degree of their members' syntactic applicability, which is, as Boas claims, correlated with the gradual increase in the degree of the verbs' descriptivity.

With the exception of the first group with walk representing its single member, the groups recognized by Boas are not homogeneous as regards the syntactic behaviour of their members. As can be seen from Boas's (2008: 34) evaluation of the verbs' syntactic applicability given in the tables below, the variability is especially apparent in the second and third groups.

Table 1. Syntactic applicability of walk (the only verb representing the $1^{\text {st }}$ group)

\begin{tabular}{|l|c|}
\hline & walk \\
\hline Location PP & + \\
\hline Resultative Construction & + \\
\hline Caused-motion Construction & + \\
\hline Induced Action Alternation & + \\
\hline Preposition Drop Alternation & + \\
\hline
\end{tabular}

Table 2. Syntactic applicability of verbs representing the $2^{\text {nd }}$ group

\begin{tabular}{|l|c|c|c|}
\hline & jog & jump & waltz \\
\hline Location PP & + & + & + \\
\hline Resultative Construction & + & + & + \\
\hline Caused-motion Construction & + & - & + \\
\hline Induced Action Alternation & - & - & + \\
\hline Preposition Drop Alternation & + & + & - \\
\hline
\end{tabular}


Table 3. Syntactic applicability of verbs representing the 3rd group

\begin{tabular}{|l|c|c|c|c|}
\hline & bustle & hike & parade & swim \\
\hline Location PP & + & + & + & + \\
\hline Resultative Construction & + & + & $?$ & + \\
\hline Caused-motion Construction & + & - & - & - \\
\hline Induced Action Alternation & - & - & + & - \\
\hline Preposition Drop Alternation & - & + & + & + \\
\hline
\end{tabular}

Table 4. Syntactic applicability of verbs representing the $4^{\text {th }}$ group

\begin{tabular}{|l|c|c|c|c|c|c|}
\hline & amble & crawl & creep & frolic & limp & meander \\
\hline Location PP & + & + & + & + & + & + \\
\hline Resultative Construction & - & - & - & - & - & - \\
\hline Caused-motion Construction & - & - & - & - & - & - \\
\hline Induced Action Alternation & - & - & - & - & - & - \\
\hline Preposition Drop Alternation & + & - & - & - & - & - \\
\hline
\end{tabular}

\begin{tabular}{|l|c|c|c|c|c|c|}
\hline & scurry & stagger & totter & trot & wade & wander \\
\hline Location PP & + & + & + & + & + & + \\
\hline Resultative Construction & - & - & - & - & - & - \\
\hline $\begin{array}{l}\text { Caused-motion } \\
\text { Construction }\end{array}$ & - & - & - & - & - & - \\
\hline Induced Action Alternation & - & - & - & - & + & - \\
\hline $\begin{array}{l}\text { Preposition Drop } \\
\text { Alternation }\end{array}$ & - & - & - & - & - & + \\
\hline
\end{tabular}

One cannot but agree with Boas that a multi-faceted approach combining insights from frame semantics, componential analysis and verb descriptivity allows for a more elaborate description of verbal meaning. Nevertheless, what remains to be answered is which meaning components are syntactically relevant and what underlies their sensitivity to syntax. This question also gains in importance in view of the fact that some verbs are claimed to differ in the degree of descriptivity but, at the same time, they do not differ in the degree of grammatical usability (cf. Boas's analysis of the level of descriptivity of totter and stagger given above). In addition, as is apparent from the tables given above, verbs belonging to a given group do not display the same degree of syntactic usability.

However, these shortcomings notwithstanding, Boas seems to point in the right direction by positing a connection between a degree of a verb's descriptivity and a degree of its syntactic applicability. If there is such a connection, there must be some mechanism which makes certain constructions available for certain (groups of) verbs. The discussion offered here will thus attempt to shed more light on factors that play a role in verbs' syntactic applicability. For the sake of comparison 
and greater clarity, the analysis is based on the set of verbs analyzed by Boas. It focuses on structures with finite verbs, namely, the location PP construction (He walked along the street), the preposition drop alternation (He walked the street), the resultative construction (He walked himself to exhaustion), the induced action alternation (He walked the dog down the street) and the caused-motion construction (He walked her off the street). It disregards structures with non-finite verbs (zero-related nominals and adjectival passive participles).

A remark concerning the difference between the caused motion construction and the induced action alternation is in order. In the induced action alternation (He walked her down the street), the direct object argument represents a causee that is induced to move by the causer (this double-agentive construction with self-agentive verbs of locomotion is termed 'a secondary agent construction' in Kudrnáčová 2013). In the caused-motion construction (He walked her off the street), the direct object argument is a theme. It is also caused to move, but as opposed to the causee in the induced action alternation, it assumes a patientive role.

\section{Distinguishing between a Verb's Act-Nucleus and Its Modificant}

The identification of syntactically relevant components of meaning necessitates having another look at which components constitute a verb's act-nucleus and which constitute its modificant. This need arises in view of the fact that the analysis of descriptivity offered by Boas is carried out against the descriptivity of walk even in cases where the verbs in question do not elaborate the kinetic pattern of walking. Such a method is justified to the extent that walk is, as Boas points out, the most prototypical verb encoding self-motion. Nevertheless, it may, to a certain extent at least, hinder the search for syntactically relevant meaning components because it derives from the false assumption that all verbs denoting some manner of self-agentive locomotion include walk as their act-nucleus - cf. Boas's contention that "the act-nucleus of the verb strut constitutes the underlying semantics shared by all verbs evoking the Self_motion frame" and that it is "typically associated with the most prototypical verb of that frame, in this case walk" (2008: 30). The fact is that not all verbs evoking the self- motion frame are manner variants (troponyms) of walk. ${ }^{4}$ The frame includes verbs like climb, dance, fly, run or sprint, which do not elaborate the physical pattern of walking. Even the set of self-motion verbs that Boas submits to analysis comprises several verbs that are clearly not troponyms of walk either, namely, the verbs jog, jump, swim and crawl. All these verbs encode kinetic patterns largely different from that involved in walk, not to mention the fact that swim is an aqua-motion verb.

To illustrate Boas's method of using walk as a basis of analytic comparison, consider his description of verbs representing the second group (jog, jump and waltz):

"Members of the second group differ from walk in that their modificants are slightly more complex. They provide up to three additional meaning 
components specifying concepts that can either be measured on a scale (e.g., speed, level of energy, casualty), or that are binary opposites of each other (e.g., feet on the ground/feet not on the ground). For example, jog implies a higher speed than walk combined with an element of exercise. Jump denotes quickness and suddenness, implying that the feet leave the ground. In addition, both verbs express a higher energy level than walk. Waltz is different from walk in that its modificant expresses lightness, casualness, or inconsiderateness, thereby contributing more meaning to the act-nucleus." (Boas 2008: 35)

Let us first consider jog, whose modificant Boas compares with the modificant of walk. The fact, however, is that jog elaborates the kinetic pattern of running, not of walking, i.e. jog is not a troponym of walk. The meaning components 'a higher speed' and 'a higher energy level' claimed to represent its modificant are therefore part of the verb's act-nucleus: the movement must involve a relatively high level of speed combined with a relatively high level of energy if both feet are to be raised above the ground. That is, of the three components identified by Boas (a higher speed, a higher level of energy, exercise), only the meaning component 'exercise' is part of the verb's modificant. Note, however, that jog does not merely mean "run for exercise". Jogging is typically slower than running and is carried out at a steady pace (the act-nucleus of $j o g$ can thus be specified as "to run at a steady, comparatively slow pace'). This fact is reflected in language - note that we have the ranked triad 'walk-jog - run' involving an increase in speed:

Or for an excellent cardiovascular workout, walk briskly, jog, or run. (COCA)

The verb jump, the second member of the verbal group in question, denotes a multi-phase or a single-phase bipedal movement on the ground in the course of which both feet are above the ground at a certain moment (John jumped to the window). What differentiates multi-phase jumping from running is a markedly pronounced segmentation of the movement into individual kinetic quanta - one can therefore perform "a single jump" but not "a single run" (meaning 'a single step'). Jump may also denote a single-phase movement (involving two kinetic quanta, each in an opposite direction) in which the body moves along a vertical line (The child jumped up to reach an apple). Irrespective of a horizontal or a vertical axis of the movement, the verb jump designates a skeletal kinetic pattern, i.e. that which represents an irreducible set. It does not include features that add additional information to the act-nucleus and that could therefore be taken as its modificant. In other words, jump is a non-descriptive verb. This interpretation is a departure from Boas's, who takes the meaning components 'quickness', 'suddenness' and 'a higher energy level' as representing the modificant. The fact, however, is that 'quickness' and 'a higher energy level' are part of the physical core of the movement, i.e. are part of the act-nucleus - in order to get both feet above the ground, 
a certain amount of energy must be exerted and a certain amount of speed must be attained. Finally, the component 'suddenness' is not part of the lexical semantic structure of jump at all. 'Suddeness' of a movement is an aspect of meaning that specifies the position of a given movement (roughly, its unexpectancy) in a chain of events. The adverb suddenly may thus be used not only with jump (cf. ex. 4) but also with other verbs of self-agentive locomotion (cf. ex. 5):

(4) The smallest girl, Eternia, suddenly jumped forward and grabbed Cleo's foot. (BNC)

(5) There was an appalled silence in the room, broken by a choked sob from Georg, who suddenly ran out of the door. (BNC)

On account of its semantics, jump is well suited to occur with suddenly because this adverb typically relates to events of short duration (cf. Faber and Mairal Usón 1999: 152). Note in this connection that the verbs in both ex. (4) and ex. (5) belong to the category of Vendler's (1957) achievements, i.e. verbs which are only predicated for single moments of time. ${ }^{5}$

As regards waltz, its analysis against the background of walk is justified. As is evident from the description given above, Boas does not describe the "basic" sense of waltz (in which the verb represents a manner variant of dance) but the evaluative sense, in which the verb represents a manner variant of walk.

The question of which components constitute the act-nucleus and which constitute the modificant concerns, in actual fact, even the verb walk itself. Boas observes that the modificant of walk contains only very few semantic attributes; the verb "does not offer much information about the motion except for that it takes place on foot, presumably at a normal speed and with an upright posture" (2008: 35). Walk thus displays "the combination of a prominent act-nucleus with an insignificant modificant", which attests to its low degree of descriptivity (2006: 143). Nevertheless, a description along these lines raises a logical question: what is the act-nucleus of walk if 'using feet + upright posture + normal speed' is the modificant? If we extracted this purported modificant from the verb's meaning, we would be left with a core describable as the very general 'move'. This would mean that all verbs denoting a specific manner of self-agentive motion would have to be regarded as descriptive, i.e. that the hypernym move would represent the only non-descriptive member of this verbal class. A solution to the problem seems to be apparent. The components 'using feet', 'upright posture' and 'normal speed' are part of the physical core of walking, i.e. they are part of the verb's act-nucleus. In other words, walk is devoid of a modificant and classes among non-descriptive verbs. In actual fact, this is, albeit implicitly, recognized by Boas himself - recall Boas's observation mentioned above, namely, that all verbs evoking the Self_motion frame share the act-nucleus associated with the verb walk (2008: 30).

The discussion offered thus far has demonstrated that the verbs walk and jump are devoid of modifying components and represent non-descriptive verbs. There 
are, in fact, two more non-descriptive verbs in the set of verbs under Boas's analysis, namely, the verbs swim and crawl. Crawl designates the most general type of self-agentive movement on hands and feet and swim designates the most general type of self-agentive movement carried out in water. Both the verbs encode skeletal, irreducible patterns of the movement, i.e. none of the verbs' components can be taken as modifying the act-nucleus. This is a departure from Boas, who evaluates both the verbs as descriptive. In concrete terms, he depicts crawl as evoking the following concepts: slowness, laborious motion, proximity to the ground, horizontal body posture (on hands and feet), loss of control (by injured or intoxicated people), age (typical of babies), and insects (2008: 37). A closer look reveals, however, that the components 'proximity to the ground' and 'horizontal body posture (on hands and feet)' describe the skeletal physical pattern of crawling. That is, they are not part of the modificant but belong to the actnucleus. Reference to children and injured or intoxicated people cannot be taken as forming part of the modificant either. It merely helps to describe the movement - notice that 'proximity to the ground' and 'horizontal body posture (on hands and feet)' may not be enough to clearly describe what type of motion crawling is (admittedly, the reference to insects is necessary because they only have legs, not hands). The specification of types of agents thus typically forms part of dictionary definitions of $\mathrm{crawl}$. The remaining concepts identified by Boas, namely, 'slowness' and 'laborious motion', are not part of the basic sense of crawl. They have a mere associative status and are utilized in the evaluative sense of $\mathrm{crawl}$, in which the verb designates a slow and laborious self-agentive movement, cf.:

(6) Lucy crawled out of bed around lunchtime, found her way up to the shower while Josie [...]. (BNC)

As regards the verb swim, Boas does not provide a description of its semantics and only classifies the verb as belonging to the third group, comprising verbs with a relatively high degree of descriptivity. One can speculate that he does so on account of the fact that swim represents quite a complicated movement involving the whole body, requires a relatively high output of energy and, in addition, specifies the medium in which the movement is executed.

As we have seen, then, the set of verbs under analysis comprises four nondescriptive verbs: walk, jump, swim and crawl. It will thus not come as a surprise to learn that all these verbs may appear in all the syntactical constructions under consideration (with one exception, which, as we shall see, can receive an independent explanation). 


\section{Syntactic Applicability of the Non-descriptive Verbs Jump, Crawl and Swim}

According to Boas (cf. Table 2), the verb jump appears in the location PP construction (He jumped across the puddle), the preposition drop alternation (He jumped the puddle) and in the resultative construction. As regards the last mentioned construction, I found examples neither in the BNC nor in the COCA; but cf. the following example from the Web (from Hemingway's Selected Letters 1917-1961):

(7) He made 22 jumps clean out of water and when he had [...]. He jumped himself to death just as Mike's fish did. (https://books.google.cz/books?isbn=0743246896)

Nevertheless, jump may be used in the induced action alternation (cf. ex. 8) and, albeit exceptionally, in the caused-motion construction (cf. ex. 9, which I owe to my colleague Stephen Hardy):

(8) The trainer jumped the tiger through the hoop.

(9) The girl jumped up and down on the table and she did it so enthusiastically that she jumped all the cups and saucers off the table.

As regards crawl: according to Boas, the verb may appear in the location PP construction (John crawled to the door) and, when supported by sufficient context, in the caused-motion construction:

(10) Kim was excited and crawled very fast. Kim crawled Pat off the blanket. (Boas 2008: 42-43)

However, crawl may also appear, even if infrequently, in the resultative construction (ex. 11) and in the preposition drop construction (ex. 12):

(11) And he's DEFINITELY a Type A personality. [...] he can crawl himself to exhaustion and he won't stop. (BNC)

(12) We literally crawled the floor to match board widths. (COCA)

In sum, then, the only construction in which crawl and jump do not occur is the induced action alternation (jump can only occur in this construction with animal causees):

(13) *John crawled the boy along the corridor (/to the window). 
*John jumped the boy across the fence (/to the window).

The reason for this restriction most probably lies in the non-prototypicality (infrequency and non-normalcy) of these motion scenarios. Strong support for this line of reasoning comes from the possibility to use jump with animal causees (a sentence like He jumped the horse over the fence expresses a frequent scenario in the animal domain). It should be added that an explanation along these lines is not novel; the first to point to prototypicality as one of the factors determining the formation of causative constructions was Shibatani (1976).

As regards swim: under Boas's account, the verb appears in the location PP construction (He swam across the Channel), in the resultative construction (He swam himself sober) and in the preposition drop alternation (He swam the Chan$n e l)$. Nevertheless, swim may also be found in the caused-motion construction (ex. 15) and in the induced action alternation (ex. 16):

(15) John swam the girl to the shore. (meaning that John held the girl and brought her to the shore while swimming)

(16) The coach swam the team hard. (Randall 2010: 262)

In sum, then, the non-descriptive status of jump, crawl, swim and, needless to add, of walk enables these verbs to enter into all the syntactical constructions in question. The only exception is the induced action alternation with jump (involving human causees) and with crawl. Nevertheless, this restriction receives an independent explanation in that it can be attributed to the operation of a pragmatic factor, the non-prototypicality of given motion scenarios.

Table 5. Non-descriptive verbs

\begin{tabular}{|l|c|c|c|c|}
\hline & walk & jump & crawl & swim \\
\hline Location PP & + & + & + & + \\
\hline Resultative Construction & + & + & + & + \\
\hline Caused-motion Construction & + & + & + & + \\
\hline Induced Action Alternation & + & $-/+$ & - & + \\
\hline Preposition Drop Alternation & + & + & + & + \\
\hline
\end{tabular}




\section{Causal Patterning of a Motion Situation in Relation to Verbal Semantics}

\subsection{Location PP Construction and Preposition Drop Alternation}

All the verbs under analysis encode some manner of locomotion and freely enter into the location PP construction. It may, however, come as a surprise to learn that all these verbs may also be found in the preposition drop alternation, despite Boas's claim to the contrary (it should be noted that some verbs, e.g. crawl or waltz, only appear in this type of construction when supported by sufficient context).

Consider illustrative examples at least for verbs which, according to Boas, are claimed not to occur in this construction: waltz, bustle, crawl, creep, frolic, limp, meander, scurry, stagger, totter, trot and wade:

(17) $[\ldots]$ and when the band went into a ballad, Bee tucked her head into Trip's shoulder and they waltzed the floor to applause and astonished laughter. (https://books.google.cz/books?isbn=0970829345)

(18) They couldn't have been as old as they seemed, for decades later, many still bustled the streets. (https://www.tes.co.uk/article.aspx?storycode=76133)

(19) The new floor has boards from the old floor. They wanted a lot of character, knots in the wood. We literally crawled the floor to match board widths. (COCA)

(20) Each time, as I retreat, I am momentarily touched by an odd, dreamy sense of well-being, as if I had been returned to childhood and, creeping the darkened hall from the bathroom, could hear my father's rhythmic snores in the distance. (COCA)

(21) Children frolic the streets in their favorites costumes, extended families picnic on the grassy median, and mothers hold their [...]. (www.neworleansonline.com/.../Mardi\%20Gras\%20is...)

(22) We all have seen men limping the streets, pock-marked from the syphilitis. (https://books.google.cz/books?isbn=1848762437)

(23) $[\ldots]$ so if they don't want to go sightseeing, you're free to meander the brick-lined streets of Barcelona tasting tapas or to spike your day with a tequila tour of Cozumel. (COCA)

(24) Normally it is busy with traffic and people scurry the streets, but now it was all empty and appeared as though everyone had vanished. (https://books.google.cz/books?isbn=1462843824) 
[...] we disembarked at Calais - a dreadful place, England's last foothold in France, nothing more than a glorified fortress packed with men-atarms and archers, who staggered the streets in their boiled leather jerkins, drinking in the many ale houses and generally looking for trouble. (COCA)

(26) The only straight AIDS victims are drug addicts, or people who get infected blood. It's all a matter of statistics. But where I live, the 'statistics' totter the streets: pale spectres of death, leaning on walking sticks, with faces made of aged parchment stretched thinly over brittle bones. (COCA)

(27) A street urchin [...] came trotting the pavement, pouring one of the favourite tunes of his native metropolis through the tube of a penny-whistle [...]. (https://books.google.cz/books?isbn=1465510591)

We can wade the river at the shallows. (BNC)

While the preposition drop construction is open for all the verbs under analysis, the resultative construction, the caused-motion construction and the induced action alternation are open for some verbs only. The reason for this striking difference in the constructions' availability should apparently be sought in the causative structuration of the motion situation as encoded in them. As with the location PP construction (and in contrast to the resultative construction, the caused-motion construction and the induced action alternation), the preposition drop alternation does not encode a causative motion situation. Although, taken generally, participants in the direct object position are force recipients in a causal chain of events (e.g., Langacker 1987, Rappaport Hovav and Levin 2001), the path assuming a direct object position is not conceptualized as a receiver of energy transmitted from the mover. In other words, the path is not causally affected by the movement (cf. also Kudrnáčová 2015), which makes the preposition drop alternation available for both non-descriptive and descriptive verbs. ${ }^{6}$

\subsection{Resultative Construction, Caused-motion Construction and Induced Action Alternation}

Although these constructions are instantiations of different multiple argument realizations (and as such represent different form-meaning pairings), they all encode causative (hence complex, bi-eventive) events; they are all instances of what Levin and Rappaport Hovav (2005) refer to as 'event composition' (cf. also Wunderlich 2000). In the resultative construction (He walked himself to exhaustion), the movement carried out by the causer causes a certain state in the direct object participant (the patient). In the caused-motion construction (He walked Pat off the street), the movement carried out by the causer causes the direct object 
participant (the theme) to patiently undergo a movement. In the induced action alternation (He walked the dog down the street), the action of the causer causes the direct object participant (the causee) to agentively carry out a movement. Following Goldberg (e.g., 1998), the skeletal meaning of the constructions in question can thus be captured as follows:

resultative construction: ' $X$ CAUSES $Y$ TO BECOME $Z$ ' caused-motion construction: ' $X$ CAUSES $Y$ TO PATIENTLY MOVE $Z$ ' induced action alternation: ' $X$ CAUSES $Y$ TO AGENTIVELY MOVE $Z$ '

Additionally, and no less importantly, all these constructions include the syntactical frame 'NP-VP-NP-PP (/XP)'.

It cannot be overlooked that all the three types of construction display similar sensitivity to verbal meaning. For example, one cannot say *John staggered (/ scurried /limped) himself to exhaustion, *John staggered (/scurried /limped) the boy off the street or *John staggered (/scurried /limped) the boy to the door. The reason underlying these restrictions should thus be sought in the causal structuring of given motion situations as is expressed in the syntactic frame 'NP-VPNP-PP (/XP)', which includes a single verb and in which the direct object argument assumes the direct object position. The action lexicalized in the verb is thus predicated of both the subject argument and the direct object argument. Given the bi-eventive nature of given motion situations, this means that the syntactic frame in question necessarily involves an overlap of the causing event and the caused event. What is also important to realize is that causativity involves an operation of causal force, i.e. it involves transmission of energy from the causer to the patient (/the theme/ the causee). From the overlap of the two sub-events and from the causal nature of the motion situations in question it therefore follows that

(a) the entire action of the causer must be causally involved (in other words, all aspects of the causer's activity must play a causal role)

(b) the caused event (the patient's state/ the theme's movement/ the causee's movement) must be brought about by the causer's activity in its entirety (in other words, the caused event cannot involve any aspects that are not subject to causation)

The facts adduced in (a) and (b) explain why the transitive causative constructions under consideration are sensitive to verbs whose modificants express aspects that do not fall within the scope of the mover's conation, i.e. aspects that do not participate in the execution of the movement (cf. also Kudrnáčová 2013, 2015). Consider, for example, the semantics of the verb stagger. Its act-nucleus is represented by 'walk' and its modificant involves the following components: partial loss of control over the movement (including problems with maintaining balance), non-linearity of the path and irregularity of steps. Language presents 
the mover's translocation as effected owing to the physical core (walking), not owing to supplementary components. In other words, language conceptualizes the modificant as not part of causal force. This very fact then prevents the verb from entering into structures that include the transmission of causal force from the subject argument to the direct object argument, i.e. into transitive causative structures $(*$ He staggered himself to exhaustion, *He staggered her off the street, *He staggered her to the door).

Or, to give another example, the modificant in scurry specifies purely physical aspects of the movement (short steps, speed) and aspects that point to the state of the mover, i.e. that characterize the mover's self (hurriedness, furtiveness and perhaps impulsiveness). It is the latter set of components (i.e. that which characterizes the mover's self) that plays a crucial role in the verb's inability to enter into causative structures. Hurriedness (furtiveness, impulsiveness) fall outside the scope of the mover's conation. In other words, they are not part of those aspects of motion that fall within the mover's volition and therefore they cannot play a causal role with respect to bringing about the causee's (/the theme's) movement (*He scurried her to the door, *He scurried her off the street) or with respect to bringing about the patient's change of state (*He scurried himself to exhaustion).

In sum, then, modificants that specify aspects pertaining to the mover's physical and/or mental state are outside the scope of the mover's conation and, as such, do not act as causal agents. Support for this line of reasoning comes from the induced action alternation expressing animal movement. Verbs that are not admitted into this alternation with human causees (e.g., * John trotted her to the door, *John ambled her to the gate) may appear in it if the causee is an animal: John trotted (/ambled) the horse to the river. The crucial factor that enables these verbs to enter into this causative construction is the fact that, owing to the specific character of animal agentivity, verbs of motion do not encode information about the animal's self and only designate a specific physical pattern of the motion (cf. Kudrnáčová 2013: 80-91).

By way of concluding this discussion, it may be interesting to note that the non-causal status of supplementary meaning components also manifests itself in language in other ways. For example, manage in John managed to stagger to the house links to that part of the verb's meaning that is responsible for the traversal of the path. That is, it links to the act-nucleus, not to the modificant. The sentence thus does not mean that "John succeeded in staggering on his way to the house" but that "John succeeded in walking to the house (even though he staggered)" (cf. also Kudrnáčová 2008: 37-44). The modificant may sometimes be expressed overtly, cf. phrases like walk with a stagger (walk with a limp) or walk, staggering slightly (walk, limping slightly). 


\section{Verb Descriptivity in Relation to Syntactic Applicability}

\subsection{Verbs Displaying a High Degree of Descriptivity}

The verbs amble, creep, frolic, limp, meander, scurry, stagger, totter, trot and wander not only encode physical properties of the movement (speed, amount of energy, constellation of body parts, length of steps, regularity/irregularity of kinetic quanta, linearity/non-linearity of the path, etc.) but at the same time characterize the physical and/or mental self of the mover (hurriedness, furtiveness, inconsiderateness, aimlessness, playfulness, lack of sufficient control over the movement, easeness/difficulty with which the movement is carried out, etc.).

These verbs are high in descriptivity. Their modificants have an evaluative status in that they serve to characterize the physical/mental self of the mover. Related to this is the fact that the act-nuclei of some of these verbs (e.g., scurry, frolic or trot) are overshadowed ("bleached") by supplementary meaning components to such a degree that they do not specify a concrete type of motion. Such verbs are then best characterized as manner variants of the general 'move', not of 'walk' or 'run' (e.g., frolic may, apart from walking and running, also include hopping).

As discussed in the previous section, the components that specify the physical/ mental self of the mover are not part of causal force, which prevents these verbs from entering into causative constructions:

(29) *John ambled (crept/ frolicked/ limped/ meandered/ scurried/ staggered/ tottered/ trotted/ wandered) himself to exhaustion.

(30) *John ambled (crept/ frolicked/ limped/ meandered/ scurried/ staggered/ tottered/ trotted/ wandered) Peter off the street.

(31) a. *John ambled (crept/ limped/scurried/ staggered/ tottered/ trotted) Peter to the house.

b. *John frolicked (meandered/ wandered) Peter round the house.

Table 6. Verbs displaying a high degree of descriptivity

\begin{tabular}{|l|c|c|c|c|c|}
\hline & amble & creep & frolic & limp & meander \\
\hline Location PP & + & + & + & + & + \\
\hline Resultative Construction & - & - & - & - & - \\
\hline Caused-motion Construction & - & - & - & - & - \\
\hline Induced Action Alternation & - & - & - & - & - \\
\hline Preposition Drop Alternation & + & + & + & + & + \\
\hline
\end{tabular}




\begin{tabular}{|l|c|c|c|c|c|}
\hline & scurry & stagger & totter & trot & wander \\
\hline Location PP & + & + & + & + & + \\
\hline Resultative Construction & - & - & - & - & - \\
\hline Caused-motion Construction & - & - & - & - & - \\
\hline Induced Action Alternation & - & - & - & - & - \\
\hline Preposition Drop Alternation & + & + & + & + & + \\
\hline
\end{tabular}

\subsection{Verbs Displaying a Low Degree of Descriptivity}

As opposed to the modificants of the verbs of the amble group (cf. section 7.1), the modificants of the verbs jog, hike, waltz (used to designate a specific type of dance) and wade do not specify the physical or the mental state of the mover. They provide information about strictly physical or circumstantial aspects of the movement. For example, the modificant in waltz designates the physical pattern of this specific type of dance and the modificant in wade specifies the medium in which the movement is set. Such modificants may thus be evaluated as 'objective' (non-evaluative). Symptomatically, they do not have the capacity to "bleach" the semantics of the verbs' act-nuclei, which all specify a concrete type of motion. Owing to the non-evaluative status of their modificants, the verbs of this group display a relatively low level of descriptivity.

All aspects of meaning encoded in these verbs fall within the scope of the mover's conation, which is a crucial factor predisposing these verbs to enter into transitive causative structures. On the other hand, the counter-acting factor weakening the verbs' potential to appear in these structures seems to be the non-prototypicality of given scenarios.

The act-nucleus of jog is 'to run at a steady, comparatively slow pace' and the act-nucleus of hike is 'to walk'. As regards the verbs' modificants, both jog and hike specify the purpose of the motion (exercise, recreation) and the setting of the motion (typically outdoors in jogging; the landscape in hiking). In addition, hike implies a relatively long path. As regards their behaviour, both verbs can appear in the resultative construction (exx. 32 and 33). Jog can exceptionally be found in the caused-motion construction (ex. 34); this construction is not open for hike (ex. 35). The induced action alternation seems more ready to admit jog (ex. 36) than hike (ex. 37):

(32) He had to have his knees replaced because he jogged them to death. Bodily exercise profited his knees absolutely nothing [...].

(http://www.biblicalresearchreports.com/bodilyexercise.php)

(33) We hiked ourselves to exhaustion.

(34) Kim jogged Pat off the street. (Boas 2008: 42-43) 
*Kim hiked Pat off the cliff.

(36) (?)He jogged her round the park.

(37) ?He hiked her around Scotland.

The act-nucleus of the non-evaluative waltz is 'to dance'; the modificant designates the specific kinetic pattern of this type of dance. Most probably owing to the fact that waltz denotes the most prototypical type of dance and that its modificant expresses purely physical aspects of the movement, the verb can be found in all three types of causative constructions under consideration, i.e. in the resultative construction (cf. ex. 38), in the caused-motion construction (cf. ex. 39, which I owe to my colleague Stephen Hardy) and in the induced action alternation (cf. ex. 40):

(38) She waltzed the soles off her shoes. (Levin 1993: 269)

(39) They waltzed so enthusiastically that they waltzed three people off the chair.

(40) He waltzed her around the ballroom.

Finally, the verb wade does not appear in any of the causative constructions in question: *He waded himself to exhaustion, *He waded her off the bank, ?*He waded her ashore. One can speculate that the reason lies in the non-prototypicality of these scenarios. (According to Boas, wade can appear in the induced action alternation. It is thus to be regretted that he does not provide an example.)

Table 7. Verbs displaying a low degree of descriptivity

\begin{tabular}{|l|c|c|c|c|}
\hline & jog & hike & waltz (non-evaluative) & wade \\
\hline Location PP & + & + & + & + \\
\hline Resultative Construction & + & + & + & - \\
\hline Caused-motion Construction & + & - & + & - \\
\hline Induced Action Alternation & $(+)$ & $?$ & + & $?$ \\
\hline Preposition Drop Alternation & + & + & + & + \\
\hline
\end{tabular}

\subsection{Borderline Verbs}

The verbs bustle, waltz (used in its evaluative sense, i.e. "to walk lightly and easily, or casually and unconcernedly") and parade represent a borderline group. As with the modificants of the verbs of the amble group (cf. section 7.1), the modificants of these verbs characterize aspects pertaining to the mover's self (fussiness, hurriedness, relaxedness, proudness, ostentatiousness, etc.). What singles 
these verbs out as a separate category is the fact that they freely enter into the induced action alternation. More importantly, however, their occurrence in this type of alternation cannot be attributed to idiosyncracy in their behaviour but is an outcome of a split in their meaning. As will be explained in greater detail further in this section, the induced action alternation with these verbs severs the verb's modificant from the act-nucleus, which, in effect, enables the modificant to participate in bringing about the causee's movement, i.e. to become part of causal force.

According to Boas, bustle may appear in the resultative construction and in the caused motion construction. It seems, however, that the verb's syntactic availability needs reconsideration. First, the resultative construction with bustle seems to be only marginal at present; cf. an example from the Web (from the Complete Works of Charles Kingsley):

(41) [...] till the churchwardens and sidesmen, who never had before so goodly a company to arrange, have bustled themselves hot, and red, and frantic [...]. (https://books.google.cz/books?id=IJMfAgAAQBAJ)

Second, although it is true that bustle may be found in sentences involving caused motion, the fact is that such sentences are instantiations of the induced action alternation, not of the caused-motion construction. Consider the following example, in which the direct object argument (the reluctant boy) is not a theme that is caused to patiently move but a causee that is induced to execute a self-agentive movement:

(42) Early one evening, Malcolm bustled the reluctant boy into the car for a shopping expedition to Caldor. (COCA)

Notice, however, that neither the causer (Malcolm) nor the causee (the reluctant boy) "moves in an energetic and busy manner". The sentence expresses a scenario in which the causer acts upon the causee in an energetic and busy manner, thereby making the causee to agentively move somewhere. That is, the modificant specifies the way in which the causer acts upon the causee. What we thus have here is a special type of the induced action alternation which effects a split in the verb's meaning: the act-nucleus of the verb is attributed to the causee and the modificant is attributed to the causer. Apart from signalling the character of the relationship between the causer and the causee in social terms, the modificant expresses a (slight) imbalance in the force-dynamic patterning of the situation. That is, in contrast to the neutral variant with walk (Malcolm walked the reluctant boy into the car), the sentence with bustle implies a certain degree of coercive force.

Given the clearly descriptive status of bustle, one might be tempted to evaluate the induced action alternation with bustle as an exception attesting to idiosyncracy in the verb's behaviour. Closer scrutiny reveals, however, that the split in the verb's meaning has an important ramification: severing the modificant from the act-nucleus 
enables the modificant to play a causal role with respect to bringing about the causee's movement. In other words, the modificant becomes part of causal force.

Not surprisingly, then, bustle is not the only descriptive verb of self-agentive locomotion that characterizes the self of the mover and that can enter into this type of induced action alternation. Cf. ex. (43) with the evaluative waltz:

(43) So I waltzed him across the road and put him in a doorway and left him for somebody else to find. (BNC)

Here again, the causee is not induced to "waltz" in the sense "to walk lightly and easily, or casually and unconcernedly". The physical core of the action is ascribed to the causee's action, whereas the modificant (lightness, casualness) is ascribed to the causer's action. The function of the modificant is to signal the degree and character of causal force in the force-dynamic patterning of the situation (cf. also Kudrnáčová 2013: 62-67).

As with bustle and waltz, the verb parade in the induced action alternation also characterizes the mental self of the causer (proudness, ostentatiousness). Note, however, that parade does not undergo a split in its meaning. That is, when John parades Mary up and down the street, Mary parades up and down the street.

Table 8. Borderline verbs

\begin{tabular}{|l|c|c|c|}
\hline & bustle & waltz (evaluative) & parade \\
\hline Location PP & + & + & + \\
\hline Resultative Construction & $(+)$ & - & - \\
\hline Caused-motion Construction & - & - & - \\
\hline Induced Action Alternation & + & + & + \\
\hline Preposition Drop Alternation & + & + & + \\
\hline
\end{tabular}

\section{Summary}

The discussion offered in the paper has presented an analysis of the principled connections between verb descriptivity and verbal syntactic applicability. It has endeavoured to identify syntactically relevant components of verbal meaning and the reasons underlying their sensitivity to syntax. It has shown that, with a few exceptions, non-descriptive verbs (walk, jump, crawl and swim) can appear in all the constructions under consideration (the location PP construction, the preposition drop alternation, the resultative construction, the caused motion construction and the induced action alternation); the exceptions are attributable to the operation of a pragmatic factor, the non-prototypicality of given causal scenarios. Descriptive verbs, by contrast, are limited in their applicability. Verbs displaying a high degree of descriptivity (amble, creep, frolic, limp, meander, scurry, stagger, totter, trot and wander) include modificants that characterize the physical 
or mental self of the mover (symptomatically, these verbs have an evaluative potential). Such modificants provide information about supplementary aspects of a motion that do not fall within the scope of the causer's conation. Their inability to become part of causal force is the factor that makes the verbs unavailable for transitive causative structures (the resultative construction, the caused motion construction and the induced action alternation), which include transmission of causal energy from the subject argument to the direct object argument. Verbs displaying a low degree of descriptivity (jog, hike, wade and the non-evaluative waltz) include modificants that provide information about purely physical or circumstantial aspects of the motion (these verbs thus do not have an evaluative potential). Although these modificants express aspects that fall within the scope of the mover's conation and that, therefore, enable the verbs to enter into causative constructions, these verbs display variable behaviour with respect to their participation in transitive causative constructions. The factor weakening their availability for such structures should most probably be sought in the non-prototypicality of given causal scenarios. The verbs bustle, waltz (used in the evaluative sense) and parade represent a separate group. Although they are high in descriptivity, they all appear in the induced action alternation. The alternation with these verbs is, however, of a special type in that it effects severing of the modificant from the act-nucleus, which enables the modificant to become part of causal energy.

Restrictions imposed by transitive causative constructions on verbs indicate that the crucial factor determining the verbs' applicability lies in the interaction between verbal meaning and the causal structuration of a situation as is expressed in a given syntactical configuration with a given configuration of arguments. Strong support for this line of reasoning comes from the fact that the location PP construction and the preposition drop alternation are available for both nondescriptive and descriptive verbs.

\section{Notes}

1 For a comparative survey of several approaches to semantic verb classifications, including the FrameNet project, see Čulo et al. (2008).

2 Core frame semantic elements are conceptually necessary components of a frame which make the frame "unique and different from other frames" (Ruppenhofer et al. 2010: 19).

3 A semantic description of verbs along similar lines can be found in Dixon (1971). Dixon makes a distinction between nuclear verbs and non-nuclear verbs. For example, look is a nuclear verb and stare is non-nuclear. Whereas stare can be defined in terms of the more general look (stare can be roughly specified as "look hard"), look cannot be defined against a more general verb. In other words, the meaning of non-nuclear verbs can be specified definitionally, by appealing to the meanings of nuclear verbs. The meaning of nuclear verbs, by contrast, cannot be described against some other nuclear verbs. Nuclear verbs require a componential definition, in terms of a small set of general components of meaning (which is not to say that nuclear verbs do not display similarities that relate them to some other nuclear verbs), cf. Dixon (1971: 441).

4 Troponymy is a manner-of relation between verbs (Fellbaum 1990). For example, limp is a troponym of walk (limp can thus be paraphrased as "walk with difficulty"). Fellbaum (2002: 
54) observes that the majority of English verbs express specific manners of more general actions lexicalized in other verbs, i.e. that troponymy is a pervasive structuring feature of the English verb lexicon.

The relevance of the analysis of relations among verbs based on troponymy receives support from a cognitive semantic analysis. Deriving from an integration of spatial cognition and lexical semantics, Warglien et al. (2012) observe that force patterns describing strutting (striding, marching, sauntering, etc.) may be seen as a subset of those representing walking (2012: 172).

$5 \quad$ Under Croft's (1998: 78) aspectual account, suddenly construes the interval spanning the inception of an event and its completion as a point in time.

$6 \quad$ In resultative constructions of the They ran the pavement thin type, the direct object argument is conceptualized as a receiver of energy, i.e. as a patient.

\section{References}

Baker, Collin F. and Josef Ruppenhofer (2002) 'FrameNet's frames vs. Levin's verb classes.' In: Larson, Julie and Mary Paster (eds.) Proceedings of the 28th Annual Meeting of the Berkeley Linguistics Society. Berkeley, CA: Berkeley Linguistics Society, 27-38.

Boas, Hans C. (2006) 'A frame-semantic approach to identifying syntactically relevant elements of meaning.' In: Steiner, Petra C., Hans C. Boas and Stefan J. Schierholz (eds.) Contrastive Studies and Valency: Studies in Honor of Hans Ulrich Boas. Frankfurt am Main: Peter Lang, 119-149.

Boas, Hans C. (2008) 'Towards a frame-constructional approach to verb classification.' In: Acevedo, Eulalia S. and Francisco J. Cortés Rodríguez (eds.) Grammar, Constructions, and Interfaces. Special issue of Revista Canaria de Estudios Ingleses 57: 17-47.

Boas, Hans C. (2011) 'A frame-semantic approach to syntactic alternations: The case of build verbs.' In: Guerrero Medina, Pilar (ed.) Morphosyntactic Alternations in English. Sheffield: Equinox, 207-234.

Croft, William (1998) 'The structure of events and the structure of language.' In: Tomasello, Michael (ed.) The New Psychology of Language: Cognitive and Functional Approaches to Language Structure. Mahwah, N. J.: Lawrence Erlbaum, 67-92.

Croft, William (2012) Verbs: Aspect and Causal Structure. Oxford: Oxford University Press.

Čulo, Oliver, Katrin Erk, Sebastian Padó and Sabine Schulte im Walde (2008) 'Comparing and combining semantic verb classifications.' Language Resources and Evaluation 42(3): 265-291.

Dixon, Robert M. W. (1971) 'A method of semantic description.' In: Steinberg, Danny D. and Leon A. Jakobovits (eds.) Semantics: An Interdisciplinary Reader in Philosophy, Linguistics and Psychology. Cambridge: Cambridge University Press, 436-471.

Dowty, David R. (1979) Word Meaning and Montague Grammar: The Semantics of Verbs and Times in Generative Semantics and in Montague's PTQ. Dordrecht: D. Reidel.

Faber, Pamela B. and Ricardo Mairal Usón (1999) Constructing a Lexicon of English Verbs. Berlin: Mouton de Gruyter.

Fellbaum, Christiane (1990) 'English verbs as a semantic net.' International Journal of Lexicography 3(4): 278-301.

Fellbaum, Christiane (2002) 'Autotroponymy.' In: Ravin, Yael and Claudia Leacock (eds.) Polysemy: Theoretical and Computational Approaches. Oxford: Oxford University Press, 52-67.

Fillmore, Charles J. (1982) 'Frame semantics.' In: The Linguistic Society of Korea (ed.) Linguistics in the Morning Calm. Seoul: Hanshin Publishing, 111-137.

Fillmore, Charles J. (1985) 'Frames and the semantics of understanding.' Quaderni di Semantica 6(2): 222-254.

Goldberg, Adele E. (1998) 'Patterns of experience in patterns of language.' In: Tomasello, Michael (ed.) The New Psychology of Language: Cognitive and Functional Approaches to Language Structure. Mahwah, N.J.: Lawrence Erlbaum, 203-219. 
Goldberg, Adele E. (2002) 'Surface generalizations: An alternative to alternations.' Cognitive Linguistics 13(4): 327-356.

Jackendoff, Ray (1983) Semantics and Cognition. Cambridge, MA: MIT Press.

Jackendoff, Ray (1990) Semantic Structures. Cambridge, MA: MIT Press.

Kudrnáčová, Naděžda (2008) Directed Motion at the Syntax-Semantics Interface. Brno: Masaryk University.

Kudrnáčová, Naděžda (2013) Caused Motion: Secondary Agent Constructions. Brno: Masaryk University.

Kudrnáčová, Naděžda (2015) 'On the holistic status of direct object participants.' Ostrava Journal of English Philology 7(1): 57-67.

Langacker, Ronald W. (1987) Foundations of Cognitive Grammar, Vol. 1: Theoretical Prerequisites. Stanford: Stanford University Press.

Levin, Beth (1993) English Verb Classes and Alternations: A Preliminary Investigation. Chicago: University of Chicago Press.

Levin, Beth and Malka Rapapport Hovav (2005) Argument Realization. Cambridge: Cambridge University Press.

Randall, Janet H. (2010) Linking: The Geometry of Argument Structure. Dordrecht: Springer.

Rappaport Hovav, Malka and Beth Levin (1998) 'Building verb meanings.' In: Butt, Miriam and Wilhelm Geuder (eds.) The Projection of Arguments: Lexical and Compositional Factors. Stanford, CA: CSLI, 97-134.

Rappaport Hovav, Malka and Beth Levin (2001) 'An event structure account of English resultatives.' Language 77(4): 766-797.

Ruppenhofer, Josef, Michael Ellsworth, Miriam R. L. Petruck, Christopher R. Johnson and Jan Scheffczyk (2010) FrameNet II: Extended Theory and Practice. Available online at: https:// framenet2.icsi.berkeley.edu/docs/r1.5/book.pdf. Accessed on 2 June, 2015.

Shibatani, Masayoshi (1976) 'The grammar of causative constructions: A conspectus.' In: Shibatani, Masayoshi (ed.) Syntax and Semantics, Vol. 6: The Grammar of Causative Constructions. New York: Academic Press, 1-40.

Snell-Hornby, Mary (1983) Verb-descriptivity in German and English: A Contrastive Study in Semantic Fields. Heidelberg: Carl Winter Universitätsverlag.

Taylor, John R. (1996) 'On running and jogging.' Cognitive Linguistics 7(1): 21-34.

Van Valin, Robert D. and Randy J. LaPolla (1997) Syntax: Structure, Meaning and Function. Cambridge: Cambridge University Press.

Vendler, Zeno (1957) 'Verbs and times.' The Philosophical Review 66(2): 143-160.

Warglien, Massimo, Peter Gärdenfors and Matthijs Westera (2012) 'Event structure, conceptual spaces and the semantics of verbs.' Theoretical Linguistics 38(3-4): 159-193.

Wunderlich, Dieter (2000) 'Predicate composition and argument extension as general options a study in the interface of semantic and conceptual structure.' In: Stiebels, Barbara and Dieter Wunderlich (eds.) Lexicon in Focus. Akademie Verlag, Berlin, 247-270.

NADĚŽDA KudRnáčová is Associate Professor at the Department of English and American Studies, Faculty of Arts, Masaryk University, Brno. Her research interests lie mainly within the fields of semantics, lexicology and the interface between syntax and semantics. Apart from numerous articles, she published two monographs: Directed Motion at the Syntax-Semantics Interface (published by Masaryk University in 2008) and Caused Motion: Secondary Agent Constructions (published by Masaryk University in 2013). She has held guest lectures at universities in Munich, Vienna, Bratislava and Pécs.

Address: doc. PhDr. Naděžda Kudrnáčová, CSc., Department of English and American Studies, Faculty of Arts, Masaryk University, Arna Nováka 1, 60200 Brno, Czech Republic. [email: kudrnada@phil.muni.cz] 
